\title{
Deafness, palmoplantar hyperkeratosis, and knuckle pads with male-to-male transmission: Bart-Pumphrey syndrome
}

\author{
Gisele Viana de Oliveira ${ }^{1}$, Carlos Eduardo Steiner ${ }^{2}$, Maria Letícia Cintra ${ }^{3}$ \\ and Antonia Paula Marques-de-Faria ${ }^{2}$ \\ ${ }^{I}$ Departamento de Dermatologia, Faculdade de Ciências Médicas, Pontifícia Universidade Católica \\ de Campinas (PUC-Campinas), Campinas, SP Brazil. \\ ${ }^{2}$ Departamento de Genética Médica, Faculdade de Ciências Médicas, Universidade Estadual de Campinas \\ (Unicamp), Campinas, SP, Brazil. \\ ${ }^{3}$ Departamento de Anatomia Patológica, Faculdade de Ciências Médicas, Universidade Estadual \\ de Campinas (Unicamp), Campinas, SP, Brazil.
}

\begin{abstract}
We report on a 22-year-old male patient and his father, both presenting with congenital sensorineural deafness, diffuse palmoplantar keratoderma and knuckle pads. These findings are similar to those previously described in the Bart-Pumphrey syndrome, a rare autosomal dominant disorder. Several conditions including keratoderma and deafness are briefly reviewed.
\end{abstract}

Key words: deafness, knuckle pads, palmoplantar keratoderma, hyperkeratosis, Bart-Pumphrey syndrome.

Received: August 26, 2002; accepted: March 18, 2003.

\section{Introduction}

An association of hereditary deafness with several dermatologic conditions, including palmoplantar hyperkeratosis, has been previously reported (Blanchet-Bardot et al., 1987; Fitzgerald and Verbov, 1996; Sharland et al., 1992). The presence of both features in addition to knuckle pads was described in the condition designated as BartPumphrey syndrome, whose other major component is leukonychia (Bart and Pumphrey, 1967). Knuckle pads are well-circumscribed papules or verrucous-like nodes on the dorsa of hands and/or feet small joints, which usually appear in childhood.

We report on a male patient with congenital sensorineural deafness, knuckle pads and palmoplantar hyperkeratosis, whose father is equally affected. Although leukonychia was absent, the case is suggesive of BartPumphrey syndrome. Several conditions that include deafness and keratoderma are reviewed.

\section{Clinical Report}

The propositus, a 22-year-old male, was the first child born to a young, non-consanguineous Brazilian couple. His

Send correspondence to Antonia Paula Marques-de-Faria. Departamento de Genética Médica, Unicamp, Caixa Postal 6111, 13084-971 Campinas, SP, Brazil. Phone +55 (19) 3788-8907, fax +55 (19) 3788-8909. E-mail: dgmfcm @unicamp.br. sister and his two paternal and two maternal half sibs were all normal, but his father presented the same clinical picture (Figures 1 and 2) His mother is deceased, and none of the close relatives had complete information about pregnancy, delivery, and early development. They seem to have been normal, except for deaf-mutism, suggesting congenital deafness. At the age of three years, verrucous-like nodes appeared on the dorsa of the patient's hands and feet, in association with a thickening of palms and soles.

On clinical examination, the patient presented stature of $170 \mathrm{~cm}$, weight of $63 \mathrm{~kg}$, occipital-frontal-circumference of $54 \mathrm{~cm}$ (all within normal range), and no remarkable dysmorphic features. Dermatological evaluation revealed diffuse dry skin texture, more evident on the shoulders, diffuse palmoplantar hyperkeratosis, and knuckle pads over the metacarpophalangeal, metatarsophalangeal, and interphalangeal joints of hands and feet (Figure 2). Koebner phenomenon was observed in the anterior part of the leg, in an area where he referred a superficial traumatism. His father presented the same abnormalities, i.e., congenital deafness, palmoplantar hyperkeratosis and knuckle pads on hands and feet. Nail shape and size were normal, and no leukonychia was observed.

An audiogram and a BERA (brainstem evoked response audiometry) were performed, both showing a severe sensorineural hearing loss. Chromosome analysis in peripheral blood lymphocytes using standard G-banding tech- 


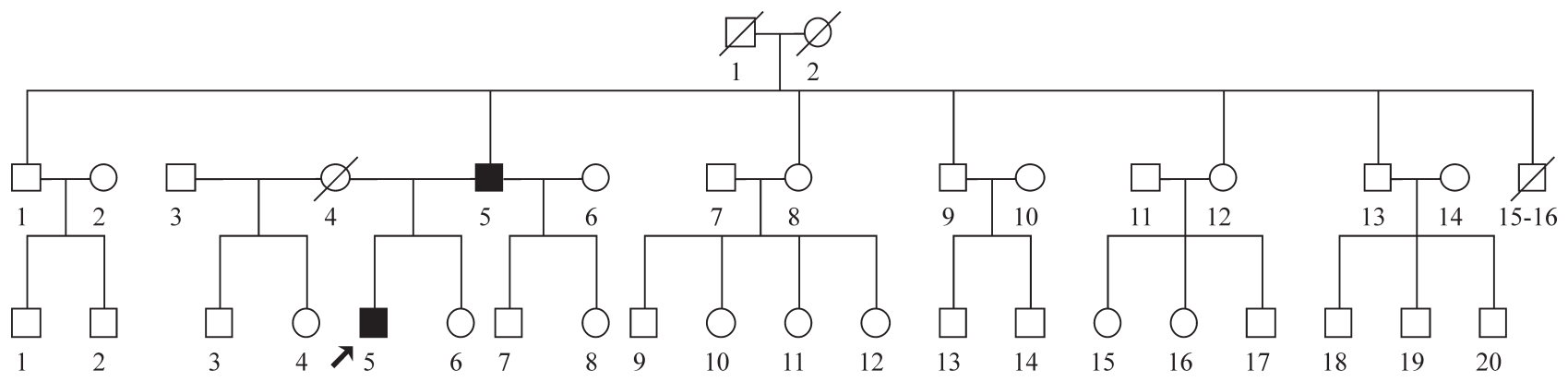

Figure 1 - Pedigree.

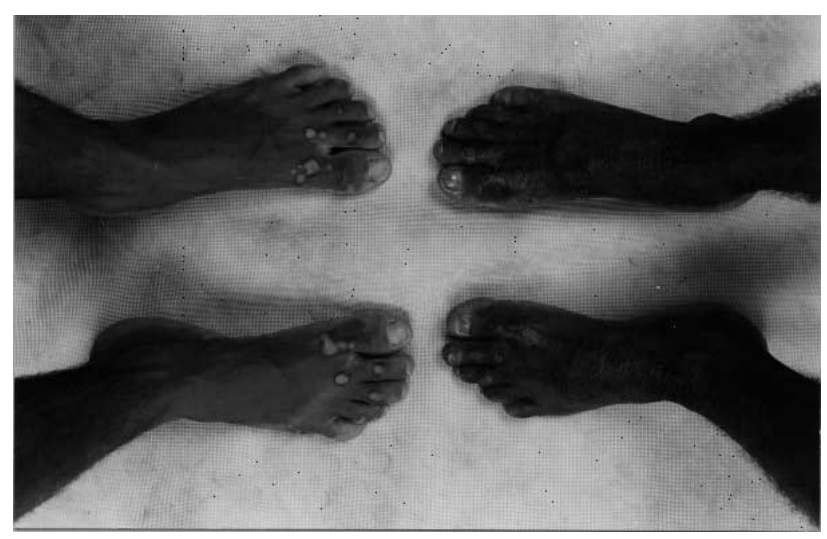

Figure 2 - Dorsa of the feet of the propositus (right) and his father (left) showing knuckle pads.

nique showed a 46,XY normal male karyotype. Plasma aminoacid chromatography resulted normal.

Routine HE skin biopsy of palms and soles of the patient and his father showed uniform hyperkeratosis (Figure $3)$. Knuckle pad biopsy revealed an epidermal depression fulfilled with orthokeratosic corneal material, without other abnormalities. Elastic fibers were preserved.

\section{Discussion}

Costa (1954) described a Brazilian family with verrucous-like lesions on the dorsa of hands and feet, in the

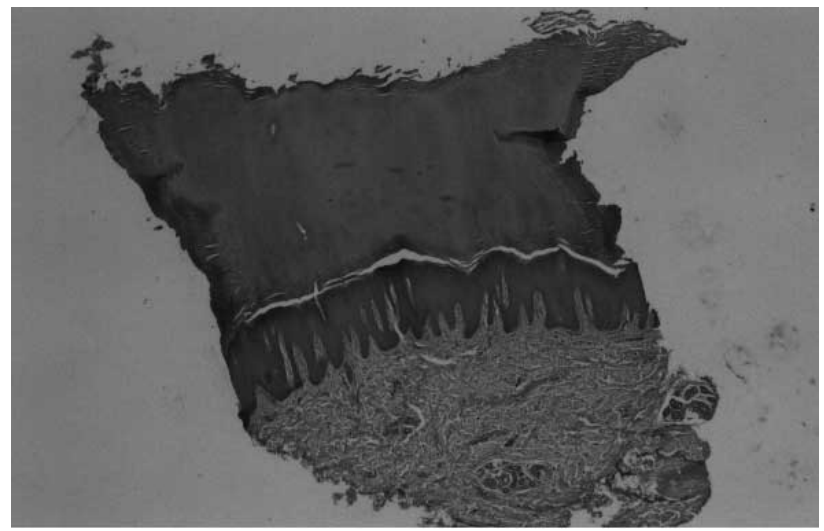

Figure 3 - Skin biopsy (HE) of palmar area showing hyperkeratosis. area corresponding to the finger joints. He called the disease "acrokeratoelastoidosis", based on the histological abnormalities found in the elastic fibers of the skin. The clinical features of the family described by this author were very similar to the present case, although deafness was not mentioned, and elastic fibers were preserved in both of our patients.

Deafness inherited as a Mendelian trait is very common, occurring as an isolated feature or in association with other congenital abnormalities. Palmoplantar keratoderma is also a common feature of several disorders (Costa, 1962; Der Kaloustian, 1993). The association of both as major components of a single disorder has been frequently described, especially in Vohwinkel syndrome, KID syndrome, HID syndrome, syndrome of palmoplantar keratoderma with deafness, and BartPumphrey syndrome.

Vohwinkel syndrome (MIM 124500) is an autosomal dominant disorder characterized by congenital deafness, palmoplantar keratoderma, and band-like constrictions of fingers and toes that may cause autoamputation (pseudo-ainhum), with onset usually in childhood. Nails, hair, and mucous membranes are usually normal (Buyse, 1990).

The term KID syndrome (MIM 148210) refers to the autosomal dominant entity that comprises keratoconjunctivitis, ichthyosiform erythroderma, sensorineural deafness, folicular hyperkeratosis, and perioral furrowed plaques (Buyse, 1990; Der Kaloustian, 1993). A recessive form was also described (MIM 242150).

HID syndrome (MIM 602540) is a condition characterized by Hystrix-like ichthyosis and deafness. It manifests right after birth with erythematous patches. Palmoplantar hyperkeratosis occurs at a mild degree. Cases of HID syndrome are generally sporadic, but one case of familial occurrence was reported (Der Kaloustian, 1993).

A form of palmoplantar keratoderma with deafness (PPKD) (MIM 148350) was described by Bititci (1975) in a Turkish family, and other cases with similar features were reported later on (Blanchet-Bardot et al., 1987; Fitzgerald and Verbov, 1996; Hatamochi et al., 1982; Sharland et al., 1992; Verbov, 1987). The clinical picture is defined as diffuse palmoplantar hyperkeratosis with onset in childhood, 
associated to late-onset, progressive bilateral sensorineural hearing loss. Knuckle pads are not described in this entity. Although autosomal dominant inheritance has been proposed, an A7445G mitochondrial point mutation was found in two families with maternally inherited PPKD, suggesting that this mutation could be associated with both hearing loss and palmoplantar keratoderma (Sevior et al., 1998). Thus, genetic heterogeneity seems likely in this condition.

Schwann (1963) described a family in which congenital deafness, early-childhood onset palmoplantar hyperkeratosis, knuckle pads and leukonychia followed an autosomal dominant pattern, with variable expressivity in the affected members. Later on, Bart and Pumphrey (1967) described another family and suggested that hearing loss was the most constant finding, while keratoderma, knuckle pads and leukonychia were variable among the affected individuals. These conclusions were reinforced by the reports of Crosby and Vidurrizaga (1976) and Ramer et al. (1994). The hearing loss was sensorineural in almost all cases, but in two patients described by Bart \& Pumphrey (1967) a mixed sensorineural and conductive impairment was observed.

Some aspects of the patients described here, such as no increase of keratoderma with age and absence of leukonychia, are different from some previous reports (Bart and Pumphrey, 1967; Crosby and Vidurrizaga, 1976; Schwann, 1963). On the other hand, two of the five individuals described by Ramer et al. (1994) did not show leukonychia. Thus, taking into account the variable expressivity of this condition, the diagnosis of BartPumphrey syndrome (MIM 149200) is suggested. The male-to-male transmission found in our patients reinforces an autosomal dominant inheritance pattern for this entity.

\section{Acknowledgments}

The authors wish to thank Dr. João de Castro Pupo Nogueira Neto and Dr. Antônio Carlos Modolo, whose helpful suggestions were very important for the study of this family, and Dr. Claudiney Costa, for audiologic evaluation. This work was supported by Fundação de Amparo à Pesquisa do Estado de São Paulo (FAPESP).

\section{References}

Bart RS and Pumphrey RE (1967) Knuckle pads, leukonychia and deafness - a dominant inherited syndrome. New Engl J Med 276:202-207.

Bititci OO (1975) Familial hereditary, progressive sensori-neural hearing loss with keratosis palmaris and plantaris. J Laryngol Otol 89:1143-1146.

Blanchet-Bardon C, Nazarro V and Puissant A (1987) Clinically specific type of focal palmoplantar keratoderma with sensorineural deafness: an entity. Dermatologica 175:148-151.

Buyse ML (1990). Birth Defects Encyclopedia. Dover: Blackwell Scientific Publications, 934 pp.

Costa OG (1954) Akrokerato-elastoidosis (a hitherto undescribed skin disease). Dermatologica 107(3):164-168.

Costa OG (1962) Acroceratoses: ceratodermias palmo-plantares. PhD Thesis, Universidade Federal de Minas Gerais, Belo Horizonte, Brazil.

Crosby EF and Vidurrizaga RH (1976) Knuckle pads, leukonychia, deafness and keratosis palmoplantaris: report of a second family. Johns Hopkins Med J 139:90-92.

Der Kaloustian VM (1993) (Autores verificar se a citação deve ser realmente por Der ou por Kaloustian)Skin. In: Human Malformation and Related Anomalies. Stevenson RE, Hall JH, Goodman RM (eds). Oxford Monographs on Medical Genetics, n. 27, New York, Oxford University Press, pp 955-963.

Fitzgerald DA and Verbov JL (1996) Hereditary palmoplantar keratoderma with deafness. Brit J Dermatol 134:939-942.

Hatamochi A, Nakagawa S, Ueki H, Miyoshi K and Iuchi I (1982) Diffuse palmoplantar keratoderma with deafness. Arch Dermatol 118:605-607.

Ramer JC, Vasily DB and Ladda RL (1994) Familial leukonychia, knuckle pads, hearing loss, and palmoplantar hyperkeratosis: an additional family with Bart-Pumphrey syndrome. J Med Genet 31:68-71.

Schwann J (1963) Keratosis palmaris et plantaris cum surditate congenita et leuconychia totali unguium. Dermatologica 126:335-353.

Sevior KB, Hatamochi A, Stewart IA, Bykhovskaya Y, AllenPowell DR, Fischel-Ghodsian N and Maw MA (1998) Mitochondrial A7445G mutation in two pedigrees with palmoplantar keratoderma and deafness. Am J Med Genet 75:179-185.

Sharland M, Bleach NR, Goberdhan PD and Patton MA (1992) Autosomal dominant palmoplantar hyperkeratosis and sensorineural deafness in three generations. J Med Genet 29:50-52.

Verbov J (1987) Palmoplantar keratoderma, deafness and atopy. Br J Dermatol 116:881-2. 